\section{Flower Bud Removal and Cytokinin Treatment Stimulate Capitulum Formation in Double-flowered Zinnias}

\author{
Daiichiro Miyajima ${ }^{1}$ \\ Faculty of Agriculture, Shinshu University, Kamiinagun, Nagano 399-4511, \\ Japan
}

Additional index words. benzyladenine, bud removal, Zinnia violacea

\begin{abstract}
The increase in the capitula of zinnia plants (Zinnia violacea Cav. ) was investigated by analyzing the production of shoots. The effects of removing the buds for capitula and application of $B A$ on the production of shoots were also evaluated. It took $\approx 40$ to 50 days from the emergence of axillary buds to the opening of the capitula at the apices of the shoots from these axillary buds. The application of BA shortened the number of days for the same process. The difference in the number of days from emergence of the axillary buds to that of the first descendant axillary buds was $\approx 25$. The total number of capitula opened was greater in plants with the bud removal treatment than in intact plants. Chemical name used: ( $N$-phenylmethyl)-1 $H$-purine-6-amine (BA).
\end{abstract}

In double-flowered zinnias, the number of seeds to be harvested is determined by the number of capitula per plant, the number of florets per capitulum, and the percentage of florets that set seeds. The number of capitula per plant is an important component of seed yield (Primack and Antonovics, 1981; Winn and Werner, 1987). In zinnias, shoots formed from axillary buds produce capitula at their apices. Capitula successively open over a long cessive opening of new capitula in zinnias is an important characteristic for bedding plants, but is not favorable for seed production. Therefore, flowering of capitula must be controlled in plants used for seed production.

\section{Materials and Methods}

A study to determine the effects of flower bud removal and application of cytokinins on the production of lateral shoots in zinnia was conducted at the farm of the Faculty of Agriculture of Shinshu Univ. in Nagano Prefecture, Japan, at an altitude of $\approx 760 \mathrm{~m}$. Seeds of the two inbred cultivars Kumamotonokagayaki, Japan), and Purple Gem, a pompon (Sakata Seed Corp., Kanagawa, Japan), were sown in a vermiculite medium in 1.2-L polyethylene pots on $16 \mathrm{Apr}$. Pots were kept in a plastic film greenhouse in which temperature and photoperiod were not controlled, but temperature was recorded (Fig. 1). The seedlings were thinned to one per pot and a $14 \mathrm{~N}-2.2 \mathrm{P}-5.8 \mathrm{~K}$ liquid fertilizer was applied weekly $\left(5 \mathrm{~g} \cdot \mathrm{L}^{-1}\right)$.

Received for publication 15 Dec. 1998. Accepted for publication 11 June 1999. The cost of publishing this paper was defrayed in part by the payment of page charges. Under postal regulations, this paper therefore must be hereby marked advertisement solely to indicate this fact.

${ }^{1}$ Present address: Faculty of Agriculture, Miyazaki University, Miyazaki, Miyazaki 889-2192, Japan (e-mail: a0a311u@cc.miyazaki-u.ac.jp). period as shoots increase in number. The suca pumila double (Takii Seed Corp., Kyoto,
On 20 June, seedlings were planted in plastic film greenhouses at a spacing of $0.8 \mathrm{~m}$ between seedlings in the row and $1.0 \mathrm{~m}$ between rows. Dates of anthesis differed among plants, but the number of newly opened capitula were counted daily on 10 plants per cultivar. Using the same 10 plants, the dates when axillary buds emerged on two tertiary lateral shoots in each plant, as well as when the capitula from these axillary buds opened, were recorded and the number of days from emergence of axillary buds to opening of capitula was calculated. Data were also collected on the number of days from emergence of the first to the last axillary bud on each shoot and from emergence of the first axillary bud to that of the first descendant axillary bud on shoots developing from these buds.

On another 10 plants per cultivar, all visible flower buds were removed on or before 14
Aug. After this date, the number of capitula opening was counted daily. The same traits of shoot production were recorded. Ten plants of each cultivar were sprayed with 100 or 200 $\mathrm{mg} \cdot \mathrm{L}^{-1}$ benzyladenine [BA; $(N$-phenylmethyl)$1 \mathrm{H}$-purine-6-amine] in a solution with $1 \%$ Tween 20 (40 mL per plant) when the secondary or tertiary shoots were elongating (31 July). Shoot production traits were recorded as above. Mean separation by Tukey's test was calculated for the days to shoot formation and the number of capitula opened by 13 Oct. for intact plants, plants with buds removed, and those treated with BA. In the BA-treated plants, the data from the primary to tertiary lateral shoots were excluded because the treatment occurred after this growth stage.

\section{Results and Discussion}

For both cultivars, $\approx 40$ to $50 \mathrm{~d}$ were required from emergence of axillary buds to the opening of capitula at the shoot apices (Table 1). For 'Purple Gem', the application of BA and bud removal reduced the number of days from bud emergence to flowering; in both cultivars, the interval among individuals in some treatments differed by as much as $20 \mathrm{~d}$ or more. Days required from emergence of axillary buds to emergence of the axillary buds on the resulting shoots were 27 and 25 for the control group of 'Kumamotonokagayaki' and 'Purple Gem', respectively. Therefore, emergence of axillary buds preceded the opening of capitula on each shoot. Neither removal of flower buds nor application of BA affected the time for successive flower bud emergence in 'Kumamotonokagayaki'.

Only application of BA $\left(100 \mathrm{mg} \cdot \mathrm{L}^{-1}\right)$ significantly reduced the time from emergence of axillary buds to that of the first descendant axillary buds in 'Purple Gem'. The time from the emergence of the first to the last descendant axillary buds from each shoot was not affected by the removal of buds or the application of BA in either cultivar (data not shown).

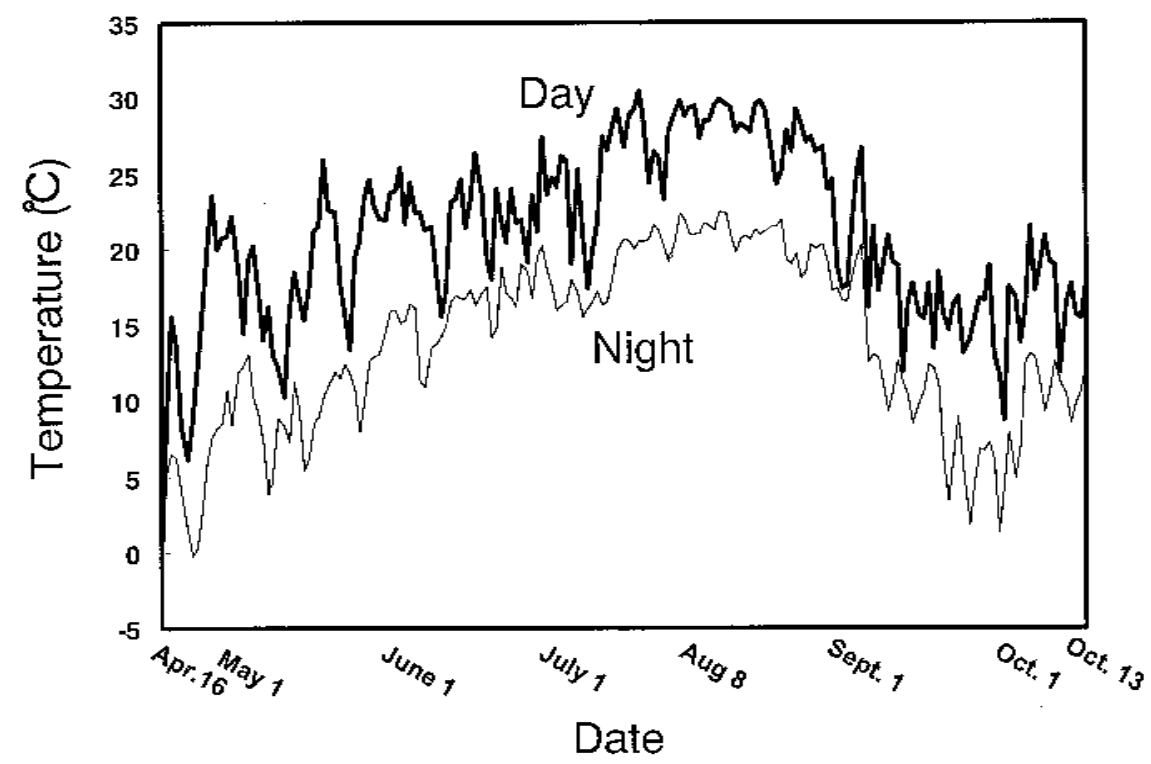

Fig. 1. Average day (0900-1800 HR) and night (2100-0600 HR) temperatures during experiments. 
Table 1. Effect of bud removal and BA application on the formation of lateral shoots in two zinnia cultivars and number of capitula that opened by 13 Oct.

\begin{tabular}{|c|c|c|c|}
\hline \multirow[b]{2}{*}{ Treatment } & \multicolumn{2}{|c|}{ Time (d) from: } & \multirow[b]{2}{*}{$\begin{array}{l}\text { No. capitula } \\
\text { by } 13 \text { Oct. }\end{array}$} \\
\hline & $\begin{array}{l}\text { Emergence of bud } \\
\text { to flowering }\end{array}$ & $\begin{array}{c}\text { Emergence of buds to } \\
\text { emergence of succeeding buds }\end{array}$ & \\
\hline \multicolumn{4}{|c|}{ Kumamotonokagayaki } \\
\hline Control & $52 a^{x}$ & 27 & $37 \mathrm{~b}$ \\
\hline Bud removal ${ }^{\mathrm{w}}$ & $47 \mathrm{ab}$ & $29^{\text {ss }}$ & $60 \mathrm{a}$ \\
\hline \multicolumn{4}{|l|}{ BA } \\
\hline $100 \mathrm{mg} \cdot \mathrm{L}^{-1}$ & $45 \mathrm{~b}$ & 25 & $31 \mathrm{~b}$ \\
\hline $200 \mathrm{mg} \cdot \mathrm{L}^{-1}$ & $49 \mathrm{ab}$ & 27 & $36 \mathrm{~b}$ \\
\hline \multicolumn{4}{|c|}{ Purple Gem } \\
\hline Control & $49 \mathrm{a}$ & $25 \mathrm{a}$ & $107 \mathrm{~b}$ \\
\hline Bud removal & $39 \mathrm{~b}$ & $21 \mathrm{ab}$ & $208 \mathrm{a}$ \\
\hline \multicolumn{4}{|l|}{ BA } \\
\hline $100 \mathrm{mg} \cdot \mathrm{L}^{-1}$ & $41 \mathrm{~b}$ & $20 \mathrm{~b}$ & $106 \mathrm{~b}$ \\
\hline $200 \mathrm{mg} \cdot \mathrm{L}^{-1}$ & $39 \mathrm{~b}$ & $22 \mathrm{ab}$ & $126 \mathrm{~b}$ \\
\hline
\end{tabular}

${ }^{2}$ Days from emergence of an axillary bud to flowering of a capitulum on a shoot developing from the bud. ${ }^{y}$ Days from emergence of an axillary bud to emergence of the first axillary bud on a shoot developing from the bud.

${ }^{x}$ Mean separation among observations and within cultivars by Tukey's studentized range test, $P \leq 0.05$.

${ }^{\text {w}}$ All buds for capitula were removed by 14 Aug., before opening.

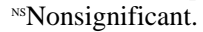

The time from emergence of axillary buds to the opening of capitula at the apices of shoots from these buds and from emergence of axillary buds to emergence of the first descendant axillary buds were shorter for 'Purple Gem' than for 'Kumamotonokagayaki'. Thus, shoot hierarchy developed more rapidly in 'Purple Gem'.

Cytokinins promote the lateral budbreak of shoots in many plant species (Mulgrew and Williams, 1985). In Easter cactus [Rhipsalidopsis gaertneri (Regel) Moran], BA increased the total number of flower buds per plant and delayed flowering by 2 to $3 \mathrm{~d}$ (Boyle, 1995). In my study, BA (100 mg. $\left.\mathrm{L}^{-1}\right)$ decreased the time from emergence of axillary buds to flowering in both cultivars. Increasing riod with the time of year when temperature and rainfall are optimum for seed growth. Concentrated opening of capitula also aids in seed harvest.

Manual removal of capitula required recognition of flower buds and their removal with scissors. However, both operations could be done in $1 \mathrm{~s}$. Because the number of capitula opening per day was less than one and three for 'Kumamotonokagayaki' and 'Purple Gem', respectively (data not shown), only a few seconds were required for removal of flower buds in each plant. Nevertheless, a few capitula continued to open, requiring bud removal over a long period. Research is needed to determine the optimum time interval for removal to minimize labor.

\section{Literature Cited}

Boyle, T.H. 1995. BA influences flowering and drymatter partitioning in shoots of 'Crimson Giant' Easter cactus. HortScience 30:288-291.

Mulgrew, S.M. and D.J. Williams. 1985. Effect of benzyladenine on the promotion of bud development and branching of Picea pungens. HortScience 20:380-381.

biomass by applying chemicals may be difficult because resources are limited in plants. The total number of capitula that had opened by 13 Oct. was greater for plants with buds removed than for intact plants in both cultivars (Table 1), but BA treatment had no significant effect. Bud removal concentrated subsequent flowering and maturation of seeds. Generally, an increase in inflorescence size or number increases the production of fruits by enhancing the attractiveness to pollinators or pollen flow (Schemske, 1980; Stephenson, 1979; Willson et al., 1979). Pollination would be facilitated by synchronizing the periods of concentrated flowering with those when pollinators are most active. Seed quality would be increased by synchronizing the flowering pe-
Primack, R.B. and J. Antonovics. 1981. Experimental ecological genetics in Plantago. V. Components of seed yield in the ribwort plantain Plantago lanceolata L. Evolution 35:1069-1079.

Schemske, D.W. 1980. Evolution of floral display in the orchid Brassavolanodosa. Evolution 34:489493.

Stephenson, A.G. 1979. An evolutionary examination of the floral display of Catalpa speciosa (Bignoniaceae). Evolution 33:1200-1209.

Willson, M.F., L.J. Miller, and B. J. Rathcke. 1979. Floral display in phlox and geranium: Adaptive aspects. Evolution 33:52-63.

Winn, A.A. and P.A. Werner. 1987. Regulation of seed yield within and among populations of Prunella vulgaris. Ecology 68:1224-1233. 